\title{
In vitro Anti-Trypanosomal Activities of Indanone-Based Chalcones
}

Authors

Richard M. Beteck ${ }^{1}$, Lesetje J. Legoabe' ${ }^{1}$, Michelle Isaacs², Heinrich C. Hoppe ${ }^{2,3}$

Affiliations

1 Centre of Excellence for Pharmaceutical Sciences, North-West University, Potchefstroom, South Africa

2 Centre for Chemico- and Biomedicinal Research, Rhodes University, Grahamstown, South Africa

3 Department of Biochemistry and Microbiology, Rhodes University, Grahamstown, South Africa

Key words

indanones, chalcones, anti-trypanosomal, HTS, HAT

received 30.07 .2018

accepted 17.10.2018

\section{Bibliography}

DOI https://doi.org/10.1055/a-0775-0737

Published online: 16.11.2018

Drug Res 2019; 69: 337-341

(c) Georg Thieme Verlag KG Stuttgart · New York

ISSN 2194-9379

Correspondence

Richard M. Beteck

Centre of Excellence for Pharmaceutical Sciences, School of Pharmacy
North-West University

Private Bag X6001

2520 Potchefstroom

South Africa

Tel.: + 27/182/992 182

richmbi1@yahoo.com

\section{ABSTRACT}

Human African trypanosomiasis is a neglected infectious disease that affects mostly people living in the rural areas of Africa. Current treatment options are limited to just four drugs that have been in use of four to nine decades. The life-threatening toxic side-effects associated with the use of these drugs are disconcerting. Poor efficacy, low oral bioavailability, and high cost are other shortcomings of current HAT treatments. Evaluating the potentials of known hits for other therapeutic areas may be a fast and convenient method to discover new hit compounds against alternative targets. A library of 34 known indanone based chalcones was screened against T.b. brucei and nine potent hits, having $\mathrm{IC}_{50}$ values between $0.5-8.9 \mu \mathrm{M}$, were found. The SAR studies of this series could provide useful information in guiding future exploration of this class of compounds in search of more potent, safe, and low cost anti-trypanosomal agents. Graphical Abstract.

Graphical Abstract

\section{Introduction}

Human African trypanosomiasis (HAT), a neglected infectious disease that is endemic to sub-Saharan Africa [1], arises from the bite of an infected tsetse fly [2]. It is caused by two sub-species of Trypanosoma brucei, namely T.b. gambiense and T.b rhodesiense[3]. The foregoing sub-species differ in their geographical preference and pathogenicity. T.b. gambiense is solely common in west Africa and causes a chronic form of HAT [4, 5], while T.b rhodesiense is endemic to east Africa and causes an acute form of HAT [6,7]. Both forms of the disease are fatal if not treated [8].

Although tremendous success against HAT has been achieved so far, with fewer deaths attributed to it [1], it's still a public health concern with 2184 new cases reported in 2016 [9] and 60 million 
people currently at risk of contracting the disease [10] if effective control measures are lacking. It is important to note that being a neglected disease consigned to the rural areas of sub-Saharan Africa where disease surveillance is challenged by several factors [11], there exists a possibility that the burden of HAT is under-reported.

Control and treatment of HAT relies solely on four chemotherapeutic agents discovered 40 or more years ago: pentamidine, suramin, malarsorprol, and eflornithine [12]. The foregoing drugs are expensive and all suffer from poor oral bioavailability and hence must be administered intravenously [13]. This is not an ideal route of administration for a neglected disease, considering the correlate that it requires special facilities and expertise not common in disease stricken areas. Moreover, these drugs cause life threatening side effects such as hyperglycaemia, bone marrow toxicity, hypoglycaemia, and in some cases death [14]. There have also been issues of treatment failure due the emergence of parasites resistant to current treatment [15].

The aforementioned drawbacks associated with current treatment underscore the need for alternative chemotherapeutic agents against HAT.

In search of cheap anti-trypanosomal agents, we decided to subject our library of synthetic cyclic chalcone analogues to screening against T.b. brucei.

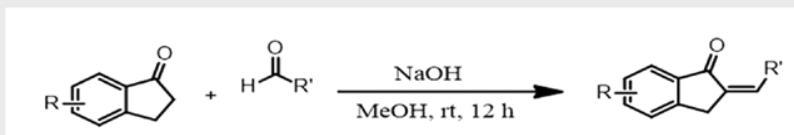

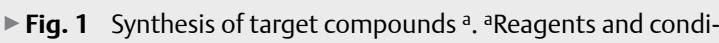
tions: $\mathrm{NaOH}, \mathrm{MeOH}, \mathrm{rt}, 12 \mathrm{~h}$.
Chalcones are notable in that they are easy to synthesise [16]. Moreover, the therapeutic potentials of chalcones cannot be over emphasised as compounds containing this scaffold have been published for their anti-bacterial, anti-viral and anti-malarial potentials [17-19]. These observations suggest that the chalcone class of compounds is a potential source for the discovery of cheap and potent anti-infectives.

We previously synthesised a series of indanone based chalcone analogues and evaluated their inhibitory activities against recombinant human monoamine oxidase [20]. We were further interested in evaluating the anti-trypanosomal activities of this series. We herein report potent trypanocidal compounds of the indanonebased chalcone class.

The synthesis and characterisation of compounds employed in this study have been previously reported $[19,21]$ and is depicted in $>$ Fig. 1 below. Briefly, 6/5-hydroxyl-1-indanone, 5-methoxyl-1-indanone, and 1 -indanone were reacted with appropriate aromatic aldehydes using acidic or basic methanol as solvent. The compounds were precipitated out of water and recrystallised from ethanol.

Compounds (1-34) were subjected to in vitro screening against the 427 strain of T.b. brucei to evaluate their anti-trypanosomal activities. After an incubation period of $48 \mathrm{~h}$, the numbers of parasites surviving drug exposure were determined by adding resazurin. Conversion of resazurin to resorufin by living cells was quantified in a multiwell fluorescence plate reader $\left(\mathrm{ExC}_{560} / \mathrm{Em}_{590}\right)$. Compounds were tested in duplicate wells, and a standard deviation (SD) calculated. Results are expressed as percentage (\%) viability - the resorufin fluorescence in compound-treated wells relative to untreated controls. Screening was performed at $20 \mu \mathrm{M}$ final concentration of synthesized compounds and pentamidine as the reference drug. At $20 \mu \mathrm{M}$, almost half of the series inhibited parasite viability to below $25 \%$ ( $\triangleright$ Fig. 2 ).

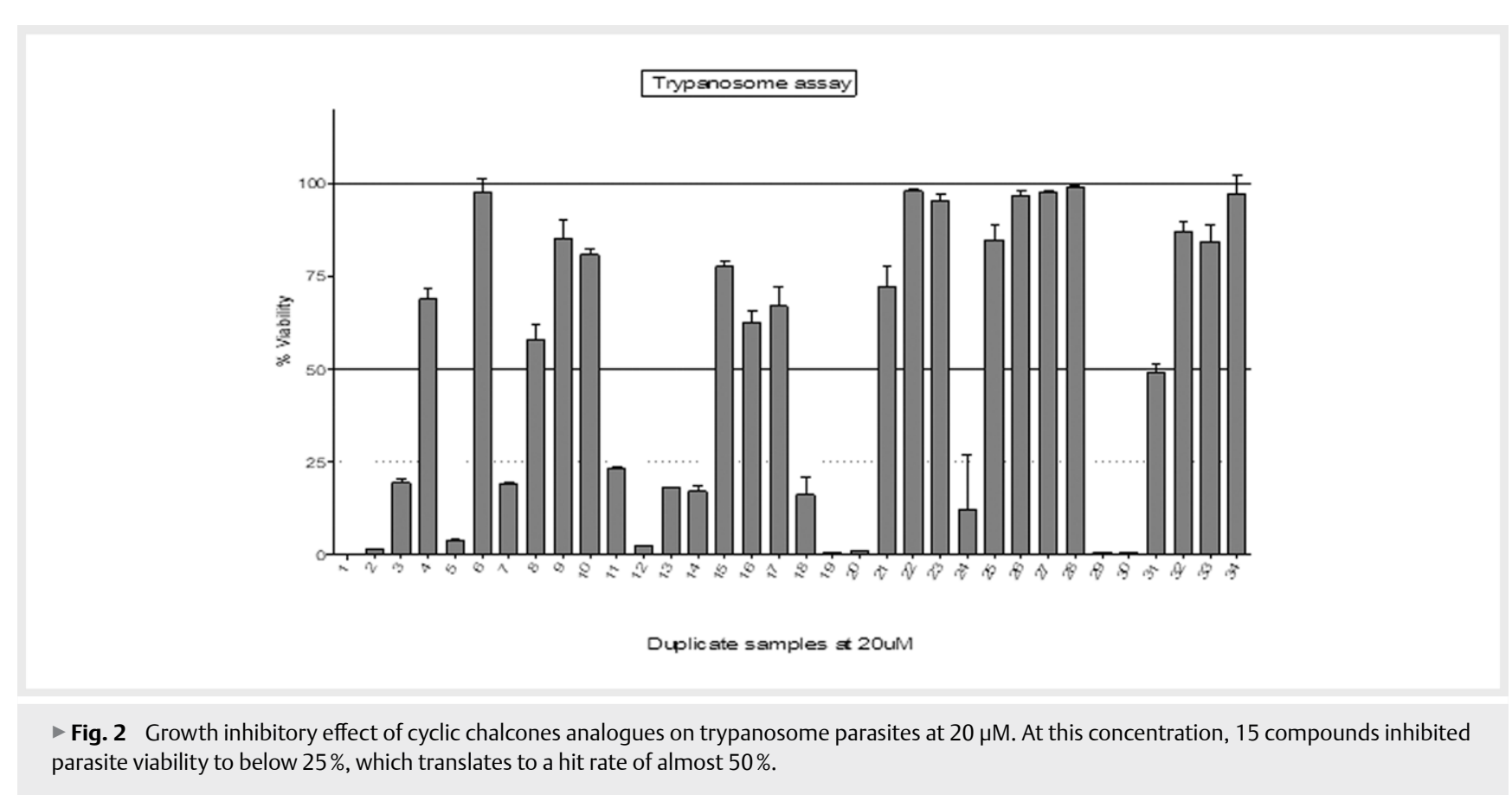




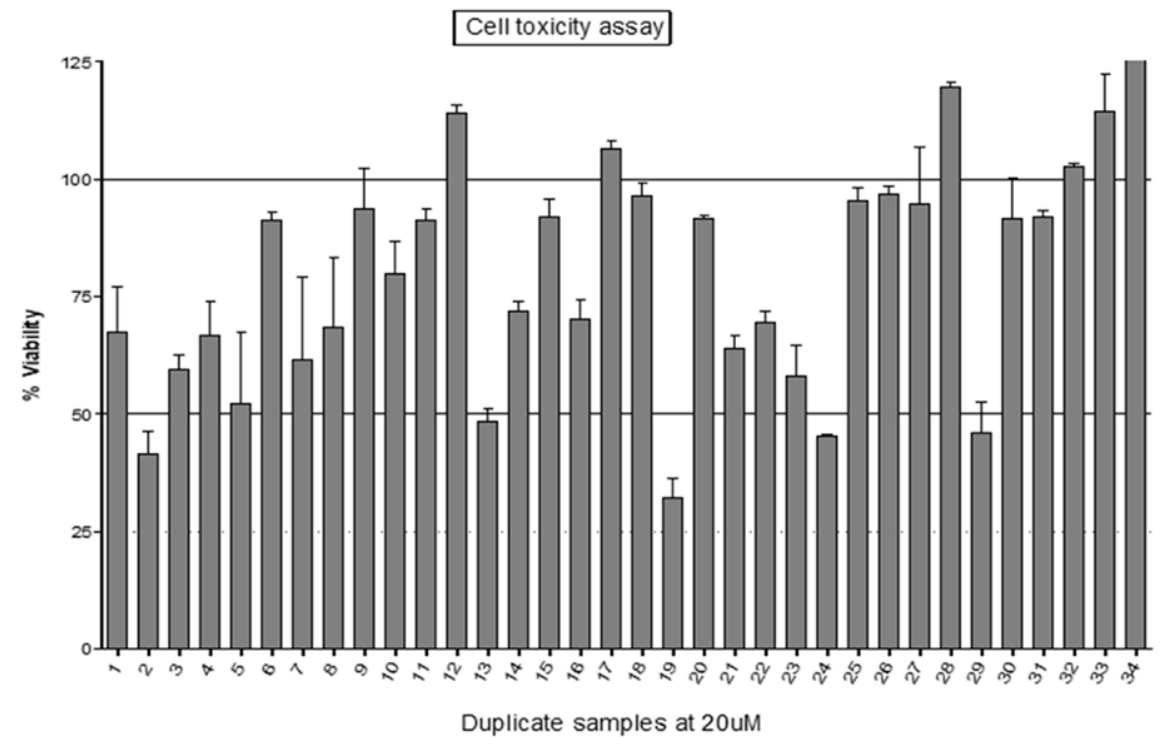

- Fig. 3 Cytotoxicity potential of compounds evaluated against HeLa cell lines at $20 \mu \mathrm{M}$.

Compounds were further screened in vitro against a human cervix adenocarcinoma (HeLa) cell line to assess their potential cytotoxicities. Screening was performed in duplicate using $20 \mu \mathrm{M}$ stock solutions of synthesised compounds and emetine as the reference drug, employing resazurin as a cell viability indicator as was done in the trypanosome assay. Compounds resulting in less than $50 \%$ Hela cell viability at $20 \mu \mathrm{M}$ were assumed to have potential cytotoxicities and hence were not taken further for $\mathrm{IC}_{50}$ determination (> Fig. 3).

Based on Hela cell viability result obtained, 9 out of the 15 compounds inhibiting parasite viability to below $25 \%$ had little effect on HeLa cell viability (> $50 \%$ cell viability at $20 \mu \mathrm{M}$ ). The observation posits that these compounds possess intrinsic anti-trypanosomal activities and pose reduced cytotoxicity risk. These promising compounds were subjected to $\mathrm{IC}_{50}$ determination against T.b. brucei and the results are summarised in \ Table 1.

In comparison with compound $\mathbf{1}\left(\mathrm{IC}_{50}, 3.0 \mu \mathrm{M}\right)$, structure activities relationship (SAR) analysis suggest that the presence of an $\mathrm{OH}$ group at position -5 of ring $\mathrm{A}$ with concurrent attachment of a halogen to ring $\mathbf{B}$ promotes anti-trypanosomal activities. This is evident in compound $\mathbf{3}$ for example, which has a lower $\mathrm{IC}_{50}$ value of 1.9 $\mu \mathrm{M}$. We also observed that the substitution pattern on ring $\mathbf{B}$ greatly influences activities. For instance, the substitution of a bromine atom in compound $7\left(\mathrm{IC}_{50}, 2.5 \mu \mathrm{M}\right)$ with a nitrile unit as is the case in compound $\mathbf{1 1}$ leads to almost a three-fold loss in activity $\left(\mathrm{IC}_{50}, 8.9 \mu \mathrm{M}\right)$. This suggests that electron donating groups attached to ring $\mathbf{B}$ tend to favour activity over electron withdrawing groups. Also, SAR comparison between compound $\mathbf{5}\left(\mathrm{IC}_{50}\right.$, $2.6 \mu \mathrm{M})$ and compound $12\left(\mathrm{IC}_{50}, 0.93 \mu \mathrm{M}\right)$ shows clearly that antitrypanosomal activities increase with increased halogenation of ring $\mathbf{B}$. This remark is also evident when comparing compounds $\mathbf{1 8}$ $\left(\mathrm{IC}_{50}, 3.2 \mu \mathrm{M}\right)$, which lacks a chlorine atom on ring $\mathbf{B}$ and its analogue compound $\mathbf{2 0}\left(\mathrm{IC}_{50}, 0.55 \mu \mathrm{M}\right)$ having a chlorine atom on ring $\mathbf{B}$.
The nature of ring $\mathbf{B}$ also influences anti-trypanosomal activities. Compounds wherein ring $\mathbf{B}$ is a pyridyl unit elicited potent anti-trypanosomal activities (e. g.20; $\mathrm{IC}_{50}, 0.55 \mu \mathrm{M}$ ), which in most cases were superior to those of phenyl analogues (e. g.5; $I C_{50}$, $2.6 \mu \mathrm{M})$. Comparing compound $18\left(\mathrm{IC}_{50}, 3.2 \mu \mathrm{M}\right)$ and 21 $\left(\mathrm{IC}_{50} \geq 200 \mu \mathrm{M}\right)$ suggests that substituting a pyridyl, or phenyl unit with a 5 membered heteroaromatic ring leads to compounds devoid of anti-trypanosomal activities.

\section{Conclusion}

Human African trypanosomiasis is a neglected infectious disease that affects mostly people living in the rural areas of Africa. Current treatment options are limited to just four drugs that have been in use for more than four decades. The life-threatening toxic side-effects associated with the use of these drugs are alarming. Other shortcomings of current HAT treatments include poor efficacy, low oral bioavailability and high cost. All of these factors necessitate the search for new trypanocidal agents.

Being a neglected disease that affects mostly the poorest communities in sub-Saharan Africa, an ideal anti-trypanosomal agent should be relatively cheap. To this end, we decided to investigate the anti-trypanosomal potential of indanone based chalcone analogues. This compound class is cheap to obtain as it is synthesised from readily available starting materials in a simple single synthetic transformation. The antitrypanosomal activities of this series were established by screening against T.b. brucei. Nine potent hits, all having no cytotoxic effect on a HeLa cell line (>50\% cell viability at $20 \mu \mathrm{M})$, were discovered.

It is noteworthy to highlight that the physicohemical properties of a hit compound such as molecular weight, lipophilicity, total polar surface area increase during hit optimization and often lead to compounds with improved activities against the target in question, but poor leadlike properties. In an attempt to avoid poor lead-like properties at a later 
Table 1 Structures, percent viability of parasite cells and $I_{50}$ values of the most active and non-toxic compounds in vitro.

\begin{tabular}{|c|c|c|c|c|c|c|}
\hline & Compounds & & & & & \%viability $\left(\mathrm{IC}_{50} \mu \mathrm{M}\right)$ \\
\hline Entry & $\mathbf{R}$ & $\mathbf{R}^{\prime}(\mathrm{B})$ & MW & $\mathrm{Clog} P$ & tPSA & T.b. brucei \\
\hline 1 & - & phenyl & 220 & 3.5 & 17.1 & $-0.25(3.0)$ \\
\hline 2 & $6-\mathrm{OH}$ & phenyl & 236 & 3.4 & 37.3 & $1.5(\mathrm{ND})$ \\
\hline 3 & $5-\mathrm{OH}$ & 4-F-phenyl & 254 & 3.6 & 37.3 & 19.2(1.9) \\
\hline 4 & $5-\mathrm{OH}$ & 4-Cl-phenyl & 270 & 3.6 & 37.3 & 68.6(ND) \\
\hline 5 & $5-\mathrm{OH}$ & 3-Cl-phenyl & 270 & 4.1 & 37.3 & $3.6(2.6)$ \\
\hline 6 & $5-\mathrm{OH}$ & 4-Br-phenyl & 315 & 4.3 & 37.3 & 97.6(ND) \\
\hline 7 & $5-\mathrm{OH}$ & 3-Br-phenyl & 315 & 4.3 & 37.3 & $18.9(2.5)$ \\
\hline 8 & $5-\mathrm{OH}$ & 4- $\mathrm{CH}_{3}$-phenyl & 250 & 3.9 & 37.3 & 57.6(ND) \\
\hline 9 & $5-\mathrm{OH}$ & 3- $\mathrm{CH}_{3}$-phenyl & 250 & 3.9 & 37.3 & 84.9(ND) \\
\hline 10 & $5-\mathrm{OH}$ & 4-CN-phenyl & 261 & 2.9 & 61.1 & $80.6(\mathrm{ND})$ \\
\hline 11 & $5-\mathrm{OH}$ & 3-CN-phenyl & 261 & 2.9 & 61.1 & $23.0(8.9)$ \\
\hline 12 & $5-\mathrm{OH}$ & 3,4-di-Cl-phenyl & 305 & 4.7 & 37.3 & $2.0(0.93)$ \\
\hline 13 & $5-\mathrm{OH}$ & 4-OH-phenyl & 252 & 2.8 & 57.5 & $18.0(2.9)$ \\
\hline 14 & $5-\mathrm{OH}$ & 3-OH-phenyl & 252 & 2.8 & 57.5 & 16.9(ND) \\
\hline 15 & $5-\mathrm{OH}$ & 4-OCH ${ }_{3}$-phenyl & 266 & 3.3 & 46.5 & 77.4(ND) \\
\hline 16 & $5-\mathrm{OH}$ & 4-N(CH$)_{2}$-phenyl & 279 & 3.6 & 40.5 & 62.4(ND) \\
\hline 17 & $5-\mathrm{OH}$ & 4- $\mathrm{CH}\left(\mathrm{CH}_{3}\right)_{2}$-phenyl & 278 & 4.8 & 37.3 & 66.8(ND) \\
\hline 18 & - & 3-pyridyl & 221 & 1.9 & 29.4 & $16.0(3.2)$ \\
\hline 19 & - & 2-pyridyl & 221 & 1.9 & 29.4 & $0.35(\mathrm{ND})$ \\
\hline 20 & - & 2-Cl-3-pyridyl & 255 & 2.7 & 29.4 & $0.69(\mathbf{0 . 5 5})$ \\
\hline 21 & - & 2-furanyl & 210 & 2.7 & 26.3 & 72.2(ND) \\
\hline 22 & - & 2-thiophenyl & 226 & 3.2 & 17.1 & 97.8(ND) \\
\hline 23 & - & 2-pyrroyl & 209 & 2.2 & 29.1 & 95.3(ND) \\
\hline 24 & - & 3-thiophenyl & 226 & 3.2 & 17.1 & 12.1(ND) \\
\hline 25 & - & 4-N $\left(\mathrm{CH}_{3}\right)_{2}$-phenyl & 263 & 3.7 & 20.3 & 84.5(ND) \\
\hline 26 & $5-\mathrm{OCH}_{3}$ & phenyl & 250 & 3.8 & 26.3 & 96.6(ND) \\
\hline 27 & $5-\mathrm{OCH}_{3}$ & 4- $\mathrm{N}\left(\mathrm{CH}_{3}\right)_{2}$-phenyl & 293 & 3.9 & 29.5 & 97.3(ND) \\
\hline 28 & $5-\mathrm{OCH}_{3}$ & cyclohexyl & 256 & 5.2 & 26.3 & 99.1(ND) \\
\hline 29 & $5-\mathrm{OCH}_{3}$ & 2-pyridyl & 251 & 2.3 & 38.6 & $0.31(\mathrm{ND})$ \\
\hline 30 & $5-\mathrm{OCH}_{3}$ & 3-pyridyl & 251 & 22.3 & 38.6 & $0.48(\mathrm{ND})$ \\
\hline 31 & $5-\mathrm{OCH}_{3}$ & 2-furanyl & 240 & 2.9 & 35.5 & 49.1(ND) \\
\hline 32 & $5-\mathrm{OCH}_{3}$ & 2-thiophenyl & 256 & 3.4 & 26.3 & 86.9(ND) \\
\hline 33 & $5-\mathrm{OCH}_{3}$ & 5- $\mathrm{CH}_{3}$-2-furanyl & 254 & 3.4 & 35.5 & 84.2(ND) \\
\hline 34 & $5-\mathrm{OCH}_{3}$ & 5-Br-2-furanyl & 319 & 3.8 & 35.5 & 97.0(ND) \\
\hline PE & - & - & - & - & - & $(0.0095)$ \\
\hline
\end{tabular}

stage of drug discovery, it has been widely recommended that lead-like hits be prioritised as starting point for hit optimization. Lead-like hits are compounds having molecular weight $\leq 350, \mathrm{Clog} P \leq 4.2$ and $\mathrm{tPSA} \leq 90$ $\AA^{2}$. Property profiling of our hit series ( $\vee$ Table 1 ) shows that they meet the criteria set out for lead-like hits, making them worth considering for further hit optimization studies.

\section{Acknowledgements}

The authors acknowledge the financial support by North-West University, Potchefsoom campus towards this research. The bioassay component of the project was funded by the South African Medical Research Council (MRC) with funds from National Treasury under its Economic Competitiveness and Support Package awarded to Prof. Hoppe. 


\section{Conflict of Interest}

No conflict of interest has been declared by the authors.

\section{References}

[1] http://www.who.int/neglected_diseases/diseases/en/ Accessed on 14.08.2017

[2] Steverding D. The history of African trypanosomiasis. Parasites \& Vectors 2008; 1: 3

[3] Wang X, Inaok shows that they meet the a D, Shiba T et al. Expression, purification, and crystallization of type 1 isocitrate dehydrogenase from Trypanosoma brucei brucei. Protein Expr Purif 2017; 138: 56-62

[4] Gordhan H, Patrick S, Swasy M et al. Evaluation of substituted ebselen derivatives as potential trypanocidal agents. Bioorg. Med. Chem. Lett 2017; 27: 537-541

[5] Beig M, Oellien F, Garoff L et al. Trypanothione reductase: A target protein for a combined in vitro and in silico screening approach. PLoS Negl Trop Dis 2015; 9: e0003773

[6] Kuepfer I, Hhary E, Allan M et al. Clinical presentation of T.b. rhodesiense sleeping sickness in second stage patients from Tanzania and Uganda. PLoS Negl Trop Dis 2011; 5: e968

[7] Wamwiri F, Changasi R. tsetse flies (glossina) as vectors of human african trypanosomiasis: A review. Biomed Res. Int 2016; 2016; 1-8

[8] Kennedy P. Clinical features, diagnosis, and treatment of human African trypanosomiasis (sleeping sickness). Lancet Neurol 2013; 12: 186-194

[9] http://www.who.int/mediacentre/factsheets/fs259/en/ Accessed on 14.08.2017

[10] Tran H, Zheng Z, Wen X et al. Synthesis and activity of nucleoside-based antiprotozoan compounds. Bioorg. Med. Chem 2017; 25: 2091-2104
[11] Choi ], Cho Y, Shim E et al. Web-based infectious disease surveillance systems and public health perspectives: A systematic review. BMC Public Health 2016; 16: 1238

[12] Babokhov P, Sanyaolu A, Oyibo W et al. A current analysis of chemotherapy strategies for the treatment of human African trypanosomiasis. Pathog. Glob. Health 2013; 107: 242-252

[13] Malvy D, Chappuis F. Sleeping sickness. Clin Microbiol Infect 2011; 17: 986-995

[14] Burri C. Chemotherapy against human African trypanosomiasis: Is there a road to success? Parasito 2010; 137: 1987-1994

[15] Pohlig G, Bernhard S, Blum J et al. Efficacy and safety of pafuramidine versus pentamidine maleate for treatment of first stage sleeping sickness in a randomized, comparator-controlled, international phase 3 clinical trial. PLoS Negl Trop Dis 2016; 10: e0004363

[16] Zhou B, Xing C. Diverse molecular targets for chalcones with varied bioactivities. Med Chem (Los Angeles) 2015; 5: 388-404

[17] Hans RH, Guantai EM, Lategan C et al. Synthesis, antimalarial and antitubercular activity of acetylenic chalcones. Bioorg Med Chem Lett 2010; 20: 942-944

[18] Domínguez JN, de Domínguez NJ, Rodrigues ] et al. Synthesis and antimalarial activity of urenyl Bischalcone in vitro and in vivo. J Enzyme Inhib Med Chem 2013; 28: 1267-1273

[19] Yadav N, Dixit SK, Bhattacharya A et al. Antimalarial activity of newly synthesized chalcone derivatives in vitro. Chem Biol Drug Des 2012; 80: 340-347

[20] Nel MS, Petzer A, Petzer JP et al. 2-Benzylidene-1-indanone derivatives as inhibitors of monoamine oxidase. Bioorg Med Chem Lett 2016; 26 : 4599-4605

[21] Nel MS, Petzer A, Petzer JP et al. 2-Heteroarylidene-1-indanone derivatives as inhibitors of monoamine Oxidase. Bioorg Chem 2016; 69: $20-28$ 